\title{
Development of Themethod of Abies Wood Ethanollignin Sulfonation Using Sulfamic Acid
}

\author{
Boris N. Kuznetsov*, Natalia Yu. Vasilyeva, \\ Alexander S. Kazachenko, Galina P. Skvortsova, \\ Vladimir A. Levdansky and Maxim A. Lutoshkin \\ Institute of Chemistry and Chemical Technology SB RAS \\ FRC "Krasnoyarsk Science Center SB RAS" \\ 50/24 Akademgorodok, Krasnoyarsk, 660036, Russia
}

Received 22.12.2017, received in revised form 16.01.2018, accepted 12.02.2018

The method of obtaining of water soluble sulfated lignin based on the treatment of ethanollignin of abies wood by sulfamic acid in 1,4-dioxane medium in the presence of basic catalyst urea was developed. The introduction of sulfate groups into the structure of lignin is confirmed by data of elemental analysis and IR-spectroscopy. The developed method of sulfated lignin synthesis is more simple and safe, than the known methods.

Keywords: ethanollignin, abies wood, sulfamic acid, urea, sulfated ethanollignin, yield, sulfur content.

(C) Siberian Federal University. All rights reserved

* Corresponding author E-mail address: inm@icct.ru 


\title{
Разработка метода сульфатирования этаноллигнина древесины пихты
}

\section{с использованием сульфаминовой кислоты}

\author{
Б.Н. Кузнецов, Н.Ю. Васильева, \\ А.С. Казаченко, Г.П. Скворцова, \\ В.А. Левданский, М.А. Лутошкин \\ Институт химии и химической технологии СО РАН \\ ФИЦ «Красноярский научный центр СО РАН» \\ Россия, 660036, Красноярск, Академгородок, 50/24
}

Разработанметод получения водорастворимого сульфатированного лигнина путем обработки этаноллигнина древесины пихты сульфаминовой кислотой в 1,4-диоксане в присутствии основного катализатора мочевины. Введение сульфатных групп в структуру лигнина подтверждено данными элементного анализа и ИК-спектроскопии. Разработанный метод синтеза сульфатированного лигнина является более простым и безопасным, чем известные методы его получения.

Ключевые слова: этаноллигнин, древесина пихты, сульфатирование, сульфаминовая кислота, мочевина, сульфатированный этаноллигнин, выход, содержание серы.

\section{Введение}

Крупнотоннажным отходом целлюлозно-бумажной и гидролизной промышленности является лигнин, содержание которого в древесине составляет от 20 до 30 \% [1].

Лигнин имеет сложную аморфную структуру, состоящую из фенилпропановых фрагментов, хаотично сшитых между собой С-С- и С-О-связями [2]. В растительных клетках лигнин функционирует в качестве биологического барьера и «клея» для связывания между собой гемицеллюлоз и целлюлозы [3].

Лигнины, выделенные различными способами, отличаются по составу и свойствам как от продукта в нативной форме (протолигнина), так и друг от друга. Независимо от используемого процесса делигнификации лигнин обычно претерпевает значительные структурные изменения, следовательно, реакционная способность выделенных лигнинов может существенно отличаться от таковой, характерной для нативного лигнина древесины [2].

В последние годы разрабатываются новые способы получения целлюлозы, основанные на процессах органосольвентной варки древесины в присутствии различных органических растворителей, таких как метанол, этанол, уксусная и надмуравьиная кислоты [4]. Одной из основных предпосылок для разработки процессов органосольвентной варки выступает их более высокая экологическая безопасность по сравнению с сульфатными и сульфитными технологиями. Органосольвентные лигнины не содержат серы, обладают достаточно узким молекулярно-массовым распределением и относительно небольшой молекулярной

$$
-123-
$$


массой [5]. Они химически более активны, чем технические лигнины [6], хорошо растворяются в органических растворителях, что облегчает дальнейшую их химическую модификацию.

Хотя лигнин имеет большой потенциал в качестве возобновляемого источника топлива и ароматических химических веществ, технологии его переработки менее развиты, чем полисахаридов. В настоящее время ведется поиск новых, более эффективных способов переработки лигнинов, а также новых областей их применения [7, 8].

Одним из перспективных направлений переработки лигнина является получение производных, содержащих сульфатную группу. Наличие сульфатной группы придает растительному полимеру способность растворяться в воде и увеличивает его биоразлагаемость. Сульфатированные производные лигнина могут не только заменить широко используемые продукты химической модификации полисахаридов, но и найти применение в фармацевтике как потенциальные противовирусные препараты и антикоагулянты нового класса [9-11].

В известных способах сульфатирования лигнина $[12,13]$ используются агрессивные и токсичные сульфатирующие реагенты (серная и хлорсульфоновая кислоты, олеум, серный ангидрид и его комплексы с токсичными аминами). В отличие от перечисленных выше реагентов сульфаминовая кислота - стабильное, негигроскопичное кристаллическое вещество. Сульфаминовую кислоту получают в промышленных масштабах при взаимодействии мочевины с олеумом.

Целью данной работы являлась разработка нового, более простого и экологически менее опасного, чем традиционные, метода получения водорастворимого сульфатированного лигнина, основанного на использовании смеси сульфаминовой кислоты и мочевины в качестве сульфатирующего агента.

\section{Экспериментальная часть}

В работе использовали этаноллигнин, выделенный из древесины пихты сибирской (Ábiessibírica) по методике [14]. Выход этаноллигнина составил 9,5 мас. \% от навески древесины (30 мас. \% от исходного содержания лигнина в древесине).

Сульфатирование этаноллигнина осуществляли сульфаминовой кислотой в 1,4-диоксане в присутствии мочевины при различных соотношениях этаноллигнин/сульфаминовая кислота/ мочевина. Для этого в трехгорлой колбе, снабженной термометром, механической мешалкой, к эквимолярной смеси сульфаминовой кислоты и мочевины(сульфатирующий комплекс), нагретой до температуры 55-60 ${ }^{\circ} \mathrm{C}$, добавляли этаноллигнин при интенсивном перемешивании. Образовавшуюся смесь нагревали до температуры $80-95{ }^{\circ} \mathrm{C}$ в течение $1,5-3,5$ ч. По окончании процесса сульфатирования реакционную смесь охлаждали до комнатной температуры, растворитель декантировали, а оставшийся твердый продукт растворяли в небольшом количестве воды и нейтрализовывали водным раствором аммиака до $\mathrm{pH} 8$. Для удаления непрореагировавших реагентов продукт диализировали против воды в течение 8-10 ч., сменяя воду каждый час. Диализ проводили в целлофановом диализном мешке марки MF-503-46 MFPI (США) с размером пор 3,5 кДа. После диализа водный раствор сульфатированного лигнина упаривали досуха в вакууме на ротационном испарителе и получали твердый остаток - сульфатированный лигнин в виде аммониевой соли, содержащий 5,0-6,2 мас. \% серы. Выход водорастворимого 
сульфатированного лигнина рассчитывали как отношение массы сульфатированного лигнина к массе исходного лигнина, умноженное на $100 \%\left(\mathrm{Mc}_{\sqrt{J}} / \mathrm{M}_{Л} \cdot 100 \%\right)$. Полученный продукт хорошо растворяется в воде, имеет ограниченную растворимость в этаноле и нерастворим в 1,4-диоксане.

Элементный анализ сульфатированного лигнина осуществляли на элементном анализатоpe FlashEA-1112 (ThermoQuestItalia).

Содержание серы в образцах сульфатированного этаноллигнина пихты определяли по модифицированной методике [15] сжиганием их в токе кислорода при температуре $1000{ }^{\circ} \mathrm{C}$ c последующим поглощением продуктов сжигания 6\%-ным водным раствором пероксида водорода. Сжигание исследуемого образца идет по реакции

$$
\mathrm{R}\left(\mathrm{OSO}_{3} \mathrm{NH}_{4}\right) \mathrm{x}+2 \mathrm{xO}_{2} \rightarrow \mathrm{xSO}_{3}+\mathrm{x} / 2 \mathrm{~N}_{2}+2 \mathrm{xH}_{2} \mathrm{O}
$$

Образовавшуюся серную кислоту оттитровывали 0,01 н раствором гидроксида натрия, используя в качестве индикатора метиловый красный.

Содержание серы (мас. \%) определяли по формуле

$$
\mathrm{S}=\frac{\mathrm{a} \times 0,1630 * \mathrm{~K} \times 100 \%}{\mathrm{~b}}
$$

где а - количество 0,01 н $\mathrm{NaOH}$, пошедшее на титрование, мл; 0,1630 - количество $\mathrm{S}$ (мг), соответствующее 1 мл 0,01 н раствору $\mathrm{NaOH}$; K - поправка для приведения раствора щелочи к точному 0,01 н раствору; $\mathrm{b}$ - навеска сульфатированного лигнина, мг.

За основу расчета количества сульфатирующего комплекса была взята приблизительная эмпирическая формула елового лигнина Бьеркмана [1] в пересчете на одну фенилпропановую единицу (ФПЕ) $\mathrm{C}_{9} \mathrm{H}_{8,83} \mathrm{O}_{2,37}\left(\mathrm{OCH}_{3}\right)_{0,96}$. Одна структурная единица лигнина содержит 0,9 моль свободных алифатических гидроксильных групп, которые могут подвергаться сульфатированию.

Степень сульфатирования (X), \% рассчитывали по формуле

$$
X=\frac{184,5 S}{(32-87 \times 0,01 S) \times 0,9},
$$

где 184,5 - молярная масса структурной единицы лигнина, г/моль; S - содержание серы (мас. \%) в сульфатированном лигнине; 32 - атомная масса серы, г/моль; 0,9 - число алифатических гидроксильных групп в структурной единице исходного лигнина; 87 - разность между молярными массами группы - $\mathrm{OSO}_{3} \mathrm{NH}_{4}$ - и -OH-группы, г/моль.

ИК-спектры лигнина и сульфатированного лигнина снимали с использованием ИК-Фурье спектрометра Tensor-27 (Bruker, Германия) в области длин волн 400-4000 см ${ }^{-1}$ Обработку спектральной информации проводили по программе OPUS (версия 5.0). Твердые образцы для анализа готовили в виде таблеток в матрице $\mathrm{KBr}$ (2 мг образца / 1000 мг KBr).

\section{Результаты и обсуждение}

Известно, что сульфаминовая кислота при нагревании со спиртами образует с выходом до $22 \%$ соответствующие аммонийные соли [16]: 


$$
\mathrm{ROH}+\mathrm{HO}_{3} \mathrm{SNH}_{2} \rightarrow \mathrm{ROSO}_{3} \mathrm{NH}_{4} .
$$

Выход сульфата можно повысить до 70 мас. \%, добавляя в реакционную смесь пиридин. В процессе сульфатирования высших алифатических спиртов сульфаминовой кислотой в присутствии таких основных катализаторов, как пиридин, мочевина, тиомочевина, ацетамид и пиколин, наиболее эффективным катализатором является мочевина. Особенность сульфаминовой кислоты в том то, что она не реагирует с двойными связями и ароматическими соединениями, селективно сульфатирует только спиртовые группы [17]. Увеличение реакционной способности сульфаминовой кислоты в присутствии основных катализаторов объясняется образованием донорно-акцепторного комплекса, обладающего повышенной реакционной способностью к сульфатированию:

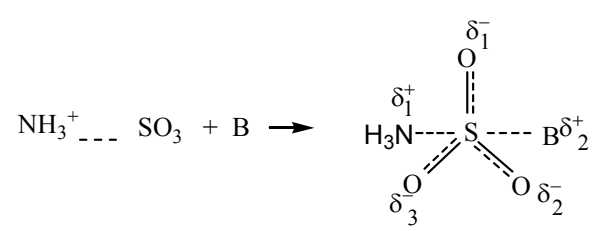

Наличие в элементарных звеньях лигнина гидроксильных групп послужило основанием для использования мочевины при его сульфатировании сульфаминовой кислотой.

Впервые реакцию сульфатирования этаноллигнина, выделенного из древесины пихты сибирской, проводили сульфаминовой кислотой в присутствии мочевины в среде 1,4-диоксана. Сульфат лигнина выделяли в виде аммонийной соли. На рис. 1 представлена схема реакции сульфатирования структурной единицы лигнина.

Сульфатирование лигнина осуществляли при температуре $80-95{ }^{\circ} \mathrm{C}$ при варьировании соотношения количества лигнина (моль ОН групп) к количеству сульфатирующего комплекса (СК, моль) и времени реакции. Условия реакции и результаты исследования - содержание серы, степень сульфатирования лигнина и выход сульфата лигнина - представлены в табл. 1.

Из полученных данных следует, что высокая степень сульфатирования (45,8-47,8 \%) наблюдается при сульфатировании этаноллигнина в течение 2,5-3,5 ч и соотношении лигнинсульфатирующий комплекс 1:1,4-1,6. Увеличение количества сульфатирующего комплекса до соотношения (лигнин:СК) равного 1:2,0 приводит к незначительному увеличению выхода сульфатированного этаноллигнина и почти не влияет на степень его сульфатирования. Этот

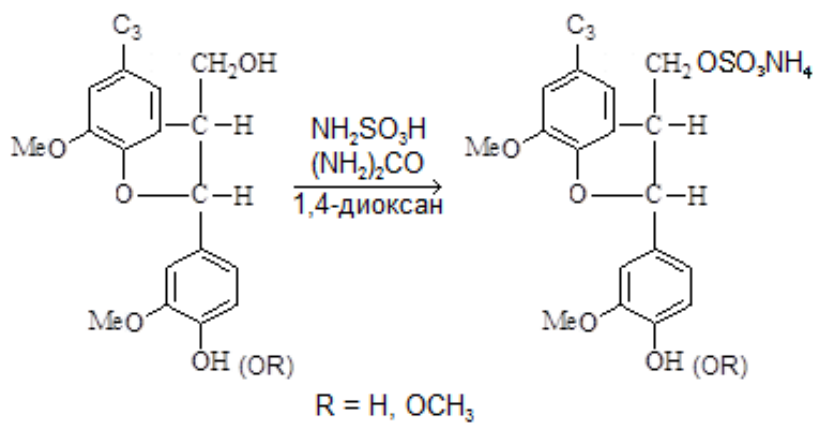

Рис. 1. Схема реакции сульфатирования структурной единицы лигнина (на примере фенилкумарана) Fig. 1. Scheme of the reaction of sulfation of the structural unit of lignin (on the example of phenyl cumaran) 
Таблица 1. Влияние условий сульфатирования этаноллигнина пихты сульфаминовой кислотой на выход сульфатированного лигнина и степень его сульфатирования

Table 1. Influence of the sulfationconditions of ethanollignin from fir-wood by sulfamic acid on the yield of sulfated lignin and the degree of its sulfation

\begin{tabular}{|c|c|c|c|c|c|c|}
\hline $\begin{array}{c}\text { Примеры } \\
\text { № п/п }\end{array}$ & $\begin{array}{c}\text { Температура } \\
\text { реакции, }{ }^{\circ} \mathrm{C}\end{array}$ & $\begin{array}{c}\text { Время } \\
\text { реакции, ч }\end{array}$ & $\begin{array}{c}\text { Лигнин: СК, } \\
\text { моль (ОН) : } \\
\text { моль (СК) }\end{array}$ & $\begin{array}{c}\text { Содержание } \\
\text { серы, \% } \\
\text { (масс.) }\end{array}$ & $\begin{array}{c}\text { Степень } \\
\text { сульфати- } \\
\text { рования, \% }\end{array}$ & Выход ${ }^{* *}, \%$ \\
\hline 1 & 80 & 1,5 & $1: 0,8$ & 0 & 0 & 0 \\
\hline 2 & 80 & 2,5 & $1: 0,8$ & 0 & 0 & 0 \\
\hline 3 & 80 & 1,5 & $1: 1,2$ & 5,0 & 37,1 & 43,8 \\
\hline 4 & 80 & 2,5 & $1: 1,2$ & 5,5 & 41,4 & 56,0 \\
\hline 5 & 80 & 2,5 & $1: 1,4$ & 6,0 & 45,8 & 65,9 \\
\hline 6 & 80 & 3,5 & $1: 1,6$ & 6,2 & 47,8 & 66,4 \\
\hline 7 & 95 & 1,5 & $1: 0,8$ & 4,5 & 28,1 & 60,0 \\
\hline 8 & 95 & 3,0 & $1: 1,1$ & 5,2 & 38,7 & 70,2 \\
\hline 9 & 95 & 2,5 & $1: 2,0$ & 6,2 & 47,8 & 71,0 \\
\hline $10^{*}$ & 80 & 3,5 & $1: 1,6$ & 4,1 & 29,6 & 27,8 \\
\hline
\end{tabular}

Примечание: * -без катализатора; ${ }^{* *} \mathrm{Mc}_{Л} / \mathrm{M}_{Л} \cdot 100 \%$.

Note: * - without catalyst; ** $\mathrm{M}_{\mathrm{SL}} / \mathrm{M}_{\mathrm{L}} \cdot 100 \%$.

факт можно объяснить тем, что в начальный период реакция сульфатирования протекает в гомогенной среде, так как исходный лигнин растворим в 1,4-диоксане, но по мере сульфатирования образуется нерастворимый в этой среде сульфатированный этаноллигнин, который осаждается из раствора в виде твердого продукта в смеси с сульфатирующим комплексом. Увеличение температуры с 80 до $95{ }^{\circ} \mathrm{C}$ существенно не влияет на степень сульфатирования лигнина.

Установлено, что при сульфатировании этаноллигнина сульфаминовой кислотой в присутствии мочевины выход сульфата и степень сульфатирования значительно возрастают. В аналогичных условиях процесса сульфатирования $\left(80{ }^{\circ} \mathrm{C}\right.$, отношение лигнин:СК=1:1,6) катализатор мочевины увеличивается выход сульфата лигнина с 27,8 до 66,4 \% и степень сульфатирования с 29,6 до 47,8 \% (табл. 1). Наибольшее содержание серы (6,0-6,2 мас. \%) обнаружено в образцах сульфатированного этаноллигнина, полученных при температуре сульфатирования $80{ }^{\circ} \mathrm{C}$ и соотношении лигнин:сульфатирующий комплекс, равном 1:1,4-1,6 моль (ОН) : моль (СК), и продолжительности реакции 3,0-3,5 ч.

В отличие от исходного этаноллигнина в ИК-спектрах аммонийных солей сульфатов этаноллигнина (рис. 2) появляются новые интенсивные полосы поглощения в области 803-861 см-1, соответствующие $\mathrm{C}-\mathrm{O}-\mathrm{S}$-валентным колебаниям $\mathrm{SO}_{3}$-группы и широкие полосы поглощения в области 1270-1200 см-1, соответствующей асимметричным валентным колебаниям группы $\mathrm{O}=\mathrm{S}=\mathrm{O}$ и скелетным колебаниям гваяцильного кольца [18].

Данные элементного анализа этаноллигнина и сульфатированного этаноллигнина также подтверждают введение сульфатных групп в макромолекулу этаноллигнина (состав этаноллигнина (мас. \%): С - 66,6; Н - 6,6; образца сульфатированного этаноллигнина: $\mathrm{C}-44,6 ; \mathrm{H}-6,3$; $\mathrm{S}-7,4)$. 


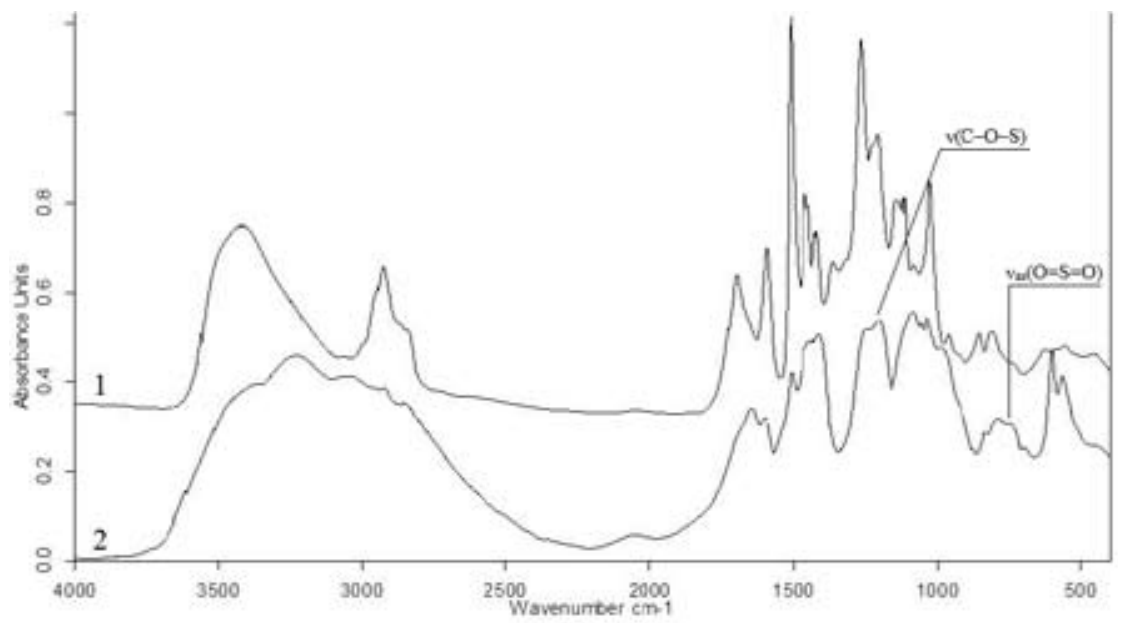

Рис. 2. ИК-спектры: этаноллигнина, выделенного из древесины пихты - (1), аммониевой соли сульфатированного этаноллигнина - (2)

Fig. 2. IR spectra: ethanollignin isolated from fir wood - (1), ammonium salt of sulfated ethanollignin - (2)

\section{Заключение}

Впервые получен водорастворимый сульфатированный лигнин путем обработки этаноллигнина древесины пихты сульфаминовой кислотой в 1,4-диоксане в присутствии основного катализатора мочевины. Наибольшее содержание серы (6,0-6,2 мас. \%) обнаружено в образцах сульфатированного этаноллигнина, полученных при температуре сульфатирования $80{ }^{\circ} \mathrm{C}$ и соотношении лигнин:сульфатирующий комплекс, равном 1:1,4-1,6 моль (ОН) : моль (СК), и продолжительности реакции 3,0-3,5 ч.

Введение сульфатных групп в структуру этаноллигнина подтверждено данными элементного анализа и ИК-спектроскопии.

Разработанный метод синтеза сульфатированного лигнина является более простым и экологически менее опасным, чем известные методы его получения.

\section{Благодарности}

Исследование выполнено при поддержке Российского научного фонда (грант № 16-1310326).

В работе использованы приборы Красноярского регионального центра коллективного пользования СО РАН. Авторы выражают благодарность И.В. Корольковой за съемку ИКспектров.

\section{Список литературы}

1. Lignin and Lignans as Renewable Raw Materials: Chemistry, Technology and Applications. Francisco G. Calvo-Flores, José A. Dobado, JoaquínIsac-García, Francisco J. Martín-Martínez. United Kingdom: John Wiley and Sons Ltd, 2015. 506 p.

2. Lignin and Lignans: Advances in Chemistry. Eds. Heitner C., Dimmel D., Schmidt J. CRC. Press: Taylor and Francis Group, 2010. 683 p. 
3. Bio-based Polymers and Composites. Eds. R.P. Wool, X.S. Sun. London: Elsevier Academic Press, 2005. $640 \mathrm{p}$.

4. Bajpai P. Recent developments in cleaner production. Environmentally friendly production of pulp and paper. Hoboken, NJ. USA: John Wiley \& Sons, Inc. 2010, p. 264-340.

5. Kuznetsov B.N., Malyar Y.N., Kuznetsova S.A., Grishechko L.I., Kazachenko A.S., Levdansky A.V., Pestunov A.V, Boyandin A.N., Celzar A. Isolation, study and application of organosolv lignins (Review). Journal of Siberian Federal University. Chemistry 2016. Vol. 4 (9), P. 454-482.

6. Torre M.J., Moral A., Hernández M.D., Cabeza E., Tijero A. Organosolv lignin for biofuel. Industrial Crops and Products 2013. Vol. 45, P. 58-63.

7. Дейнеко И.Л. Утилизация лигнинов: достижения, проблемы, и перспективы. Химия растительного сырья 2003. № 1, С. 5-20. [Deineko I.L. Utilization of lignins: achievements, problems and prospects. Chemistry of plant raw materials 2003. No. 1, P. 5-20. (In Russ.)].

8. Симонова. В.В., Шендрик Т.Г., Кузнецов Б.Н. Методы утилизации технических лигнинов. Journal of Siberian Federal University. Chemistry 2010. № 4 (3), C. 340-354. [Simonova V.V., Shendrik T.G., Kuznetsov B.N. Methods of utilization of technical lignins. Journal of Siberian Federal University. Chemistry 2010. Vol. 4 (3), P. 340-354. (In Russ.)].

9. Agrawal A., Kaushik N. Biswas S. Derivatives and Applications of Lignin - An Insight. The sci Tech journal 2014. Vol. 1 (7), P. 30-36.

10. Raghuraman A., Tiwari V., Zhao Q., Shukla D., Debnath A.K., Desai U.R.. Inhibition studies on sulfated lignin, a chemically modified biopolymer and a potential mimic of heparan sulfate. Biomacromolecules 2007. Vol. 8, P. 1759-1763.

11. Henry B.L., Desai U.R.. Sulfated low molecular weight lignins, allosteric inhibitors of coagulation proteinases via the heparin binding site, significantly alter the active site of thrombin and factor xa compared to heparin. ThrombRes 2014. Vol. 134 (5), P. 1123-1129.

12. Леонов В.В., Фурсова Е.Ю., Галочкин А.И. Гомогенный синтез сульфоэфиров лигноуглеводных материалов как перспективных реагентов для приготовления буровых растворов. Вестник Югорского гос. университета 2006. Выпуск 3, С. 78-79. [Leonov V.V., Fursova E.Yu., Galochkin A.I. Homogeneous synthesis of sulphoesters of ligno-carbohydrate materials as promising reagents for the preparation of drilling fluids. Bulletin of the Ugra State. University 2006. Issue 3, P. 78-79. (In Russ.)].

13. Лисова В.С., Резников В.М. О природе серы в продуктах сульфирования диоксанлигнина “нейтральным” пиридинсульфотриоксидом. Химия древесины 1980. № 2, С. 64-67. [Lisova B.C., Reznikov V.M. On the nature of sulfur in the products of sulfonation of dioxanelignin with "neutral" pyridinsulfotrioxide. Chemistry of Wood 1980. Vol. 2, P. 64-67 (InRuss.)].

14. Quesada-Medina J., López-Cremades F.J., Olivares-Carrillo P. Organosolv extraction of lignin from hydrolyzed almond shells and application of the d-value theory. Bioresource Technology 2010. Vol. 101, P. 8252-8260.

15. Черонис Н.Д., Ма Т.С. Микро- и полумикрометоды органического функционального анализа. М., 1973. 576 с. [Micro- and polumikrometody organic functional analysis. Moscow, 1973. 576 p. (in Russ.)].

16. Джильберт Э.Е. Сульфирование органических соединений. М.: Химия, 1969. 416 с. [Dzhil'bert E.E. Sulfonation of organic compounds. Moscow, 1969. 416 p. (In Russ.)].

$$
-129-
$$


17. Al-Horani R.A., Desai U.R. Chemical sulfation of small molecules - advances and challenges. Tetrahedron 2010. Vol. 66 (16), P. 2907-2918.

18. Roeges, Noel P.G. A guide to the complete interpretation of infrared spectra of organic structures. John Wiley \& Sons. Chichestes; NewYork; Bristane; Toronto; Singapore, 1995. 340 p. 